\title{
Erratum to: The Validity of a New Structured Assessment of Gastrointestinal Symptoms Scale (SAGIS) for Evaluating Symptoms in the Clinical Setting
}

\author{
N. A. Koloski ${ }^{1,2,3}$ (D) M. Jones ${ }^{4} \cdot$ J. Hammer ${ }^{1,2} \cdot$ M. von Wulffen ${ }^{1,2} \cdot$ \\ A. Shah ${ }^{1,2} \cdot$ H. Hoelz ${ }^{1}$ M. Kutyla ${ }^{1}$ D. Burger ${ }^{1}$ N. Martin ${ }^{1}$. \\ S. R. Gurusamy ${ }^{1}$ N. J. Talley ${ }^{3}$ - G. Holtmann ${ }^{1,2,5}$
}

Published online: 8 July 2017

(C) Springer Science+Business Media, LLC 2017

\section{Erratum to: Dig Dis Sci}

DOI 10.1007/s10620-017-4599-6

The original version of this article unfortunately contained a mistake. There was a typo in coauthor name. It should be M. Kutyla; instead, it was received and published as M. Kutuyla.

The original article has been corrected.

The online version of the original article can be found under doi:10.1007/s10620-017-4599-6.

G. Holtmann

G.holtmann@uq.edu.au

1 Department of Gastroenterology and Hepatology, Princess Alexandra Hospital and Translational Research Institute (TRI), Ipswich Rd, Woolloongabba, Brisbane, QLD 4102, Australia

2 Faculty of Medicine, University of Queensland, Brisbane, QLD 4072, Australia

3 Faculty of Health and Medicine, University of Newcastle, Newcastle, NSW 2308, Australia

4 Department of Psychology, Macquarie University, North Ryde, NSW 2109, Australia

5 Faculty of Health and Behavioural Sciences, University of Queensland, St Lucia, QLD 4067, Australia 